ARTICLE

Received 16 Jun 2014 | Accepted 23 Mar 2015 | Published 29 Apr 2015

DOI: $10.1038 /$ ncomms 7994

\title{
Granulocyte macrophage colony-stimulating factor is required for aortic dissection/intramural haematoma
}

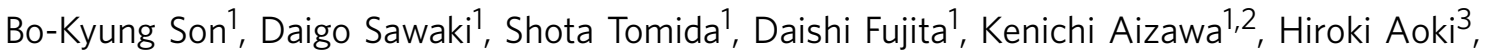 \\ Masahiro Akishita ${ }^{4}$, Ichiro Manabe ${ }^{1}$, Issei Komuro', Scott L. Friedman' ${ }^{5}$, Ryozo Nagai ${ }^{2}$ \& Toru Suzuki ${ }^{1,2,6,7}$
}

Aortic dissection and intramural haematoma comprise an aortopathy involving separation of the aortic wall. Underlying mechanisms of the condition remain unclear. Here we show that granulocyte macrophage colony-stimulating factor (GM-CSF) is a triggering molecule for this condition. Transcription factor Krüppel-like factor 6 (KLF6)-myeloid-specific conditional deficient mice exhibit this aortic phenotype when subjected to aortic inflammation. Mechanistically, KLF6 downregulates expression and secretion of GM-CSF. Administration of neutralizing antibody against GM-CSF prevents the condition in these mice. Conversely, administration of GM-CSF in combination with aortic inflammation to wild-type mice is sufficient to induce the phenotype, suggesting the general nature of effects. Moreover, patients with this condition show highly increased circulating levels of GM-CSF, which is also locally expressed in the dissected aorta. GM-CSF is therefore a key regulatory molecule causative of this aortopathy, and modulation of this cytokine might be an exploitable treatment strategy for the condition.

\footnotetext{
${ }^{1}$ Department of Cardiovascular Medicine, Graduate School of Medicine, The University of Tokyo, 7-3-1 Bunkyo-ku, Tokyo 113-8655, Japan. ${ }^{2}$ Jichi Medical University, 3311-1 Yakushiji, Shimotsuke-shi, Tochigi-ken 329-0498, Japan. ${ }^{3}$ Cardiovascular Research Institute, Kurume University, 67 Asahi-machi Kurume-shi, Fukuoka-ken 830-0011, Japan. ${ }^{4}$ Department of Geriatric Medicine, Graduate School of Medicine, The University of Tokyo, 7-3-1 Bunkyo-ku, Tokyo 113-8655, Japan. ${ }^{5}$ Division of Liver Disease, Department of Medicine, Icahn School of Medicine at Mount Sinai, 1428 Madison Avenue, New York, New York 10029, USA. ${ }^{6}$ Department of Cardiovascular Sciences, University of Leicester, BHF Cardiovascular Research Centre, Glenfield Hospital, Groby Road, Leicester LE3 9QP, UK. 7 National Institute for Health Research Leicester Cardiovascular Biomedical Research Unit, Glenfield Hospital, Groby Road, Glenfield, Leicester LE3 9QP, UK. Correspondence and requests for materials should be addressed to T.S. (email: ts263@le.ac.uk).
} 
A ortic dissection and intramural haematoma comprise a potentially life-threatening aortopathy involving separation of the aortic wall ${ }^{1-6}$. The two conditions are distinguished by a tear in the aortic intima as present in the former classical form of aortic dissection, which results in blood flow into the aortic wall and is absent in the latter form of intramural haematoma with bleeding confined within the aortic wall. This aortopathy is presently understood to be a continuum, with the latter a variant and precursory condition of the former ${ }^{7-}$ 9. Advancements in the understanding of genetic underpinnings (for example, ACTA2) ${ }^{10,11}$, clinical/epidemiological aspects (for example, The International Registry of Acute Aortic Dissections $($ IRAD $))^{4,5}$ as well as biochemical approaches (for example, smooth muscle biomarkers $)^{5,6}$ have been made in the last decade, but underlying mechanisms have remained obscure owing much to lack of a reliable animal model.

Recent advancements in understanding mechanisms of aortic disease have stemmed from hallmark studies in the genetically fragile Marfan aorta, which have shown that transforming growth factor $\beta$ (TGF $\beta)$ and its downstream intracellular kinase signalling pathways play a central role in the pathogenesis ${ }^{12-14}$. In contrast, an inflammatory pathway is thought to be a major component of aortic conditions in the atherosclerotic/ degenerative aorta seen in the typical elderly patient ${ }^{15,16}$. Commonalities and differences in mechanisms as well as relative contributions of underlying processes in these different aortic conditions have only begun to be unravelled. In the present study, we sought to address the underlying mechanisms of aortic dissection/intramural haematoma, and to understand the triggering mechanism of the condition.

Krüppel-like factor 6 (KLF6) is a transcription factor that has been shown to be robustly expressed in macrophages ${ }^{17}$, and to regulate inflammatory fibrotic diseases of multiple organs including the liver ${ }^{18}$ and kidney ${ }^{19}$. In the present study, we hypothesized that this factor might regulate pathogenic mechanisms underlying aortic disease, and observed that mice deficient for KLF6 in macrophages when subjected to aortic inflammation manifest aortic dissection/intramural haematoma.

Intriguingly, we find that the inflammatory cytokine, granulocyte macrophage colony-stimulating factor $(\mathrm{GM}-\mathrm{CSF})^{20}$, plays a central role in onset of this condition. Administration of neutralizing antibody against GM-CSF prevents the condition in these mice. Conversely, administration of the cytokine in combination with aortic inflammation to wild-type mice is sufficient to induce the condition, suggesting general effects. Clinically, patients with aortic dissection show elevated circulating levels of the cytokine, which is also expressed in the dissected aorta. GM-CSF is therefore a key regulatory molecule causative of aortic dissection/intramural haematoma.

\section{Results}

Aortic aneurysm with inflammation in Klf6 heterozygous mice. We initially found that mice heterozygously depleted for Klf6 manifest a phenotype of exacerbated aortic aneurysm (defined as greater than $50 \%$ increase in the external aortic diameter with a conserved aortic wall $)^{21,22}$, when subjected to aortic inflammation ( 2 weeks infusion of angiotensin II (AngII) with local application of calcium chloride $\left.\left(\mathrm{CaCl}_{2}\right)\right)$. Histological findings showed enlargement of the aortic lumen with a fragile aortic wall and further fibrotic tissue deposition compounded with marked infiltration of macrophages (Mac3-positive cells) (Fig. 1a-e). Mechanistically, increased expression of matrix metalloprotease- 9 (MMP9, as a marker of vascular remodelling) ${ }^{23}, F 4 / 80$ (as a marker of macrophages) ${ }^{24,25}$ and $I L-6$ (as a marker of inflammation) ${ }^{16,26-30}$ were seen in the aorta (Fig. 1f).
As marked infiltration of immune cells was seen in the diseased aorta of these mice, macrophages were depleted using clodronate, which abrogated the aortic phenotype with near absence of macrophage infiltration (Fig. 1g,h). Thus, immune cells including macrophages were important for aortic remodelling in this model.

$K l f 6^{f l / f l} ; L y s M$ Cre mice exhibit aortic dissection/haematoma. As the aortic condition in Klf6-deficient mice appeared to involve a dysregulated inflammatory response by macrophages, myeloidspecific Klf6-deficient mice (Klff ${ }^{l l f l}$;LysM Cre mice) were further generated, which showed specific reduction of KLF6 expression in the myeloid lineage by $70 \%$ as compared with control mice.

Klf $6^{f l / f l}$;LysM Cre mice subjected to aortic inflammation showed a similar phenotype of exacerbated abdominal aortic aneurysm to that seen in heterozygous knockout mice (Fig. 2a,b), but intriguingly, further showed suprarenal aortic dissection/intramural haematoma defined as separation of the intra-aortic wall with haematoma formation accompanied by intimal tear for dissection ${ }^{3}$ (Fig. 2c-f). Mice that died were from aortic rupture most likely secondary to aortic dissection/ intramural haematoma (Fig. 2g). This lesion also showed fibrotic tissue deposition with infiltration of Mac3-positive macrophages (Fig. 3a,b), thus confirming that the aortic phenotype in KLF6 deficiency was associated with perturbation of the inflammatory response.

Mechanistically, Klf6 $6^{f l / f l} ; L y s M$ Cre mice showed elevated expression of $I L-6$ in the aortic lesion (Fig. 3d) and elevated circulating levels (Fig. 3c). Further, macrophages obtained from bone marrow of Klff $f^{f l f l}$;LysM Cre mice exhibited increased IL-6 expression (Fig. 3e). Differences in expression were not seen in other major pro-inflammatory cytokines such as $I L-1 \beta, M C P-1$ or $T N F \alpha$ between macrophages from Klf6 $\sigma^{l / f l}$ and $K l f 6^{l l f l} ; L y s M$ mice (Fig. 3e). Immune cells in the diseased aorta of these mice were characterized by flow cytometry analysis, which showed a markedly increased population of $\mathrm{CD} 11 \mathrm{~b}^{+} \mathrm{Ly} 6 \mathrm{C}^{\text {hi }}$ inflammatory monocytes and this increase was also seen in the peripheral blood (Fig. 3f). Granulocytes (for example, neutrophils; Ly6G ${ }^{+}$cells) were not affected in number or (sub)population under basal conditions or in the setting of $\mathrm{CaCl}_{2}$ and AngII infusion (Supplementary Table 1; Supplementary Fig. 1a,c), nor was the functional activity of neutrophils, as examined by inflammatory cytokine expression such as $I L-8$ or $T N F \alpha^{31}$ (Supplementary Fig. 1e), or that of the population of dendritic cells (Lineage ${ }^{-} \mathrm{CD}_{11 c^{+}}$cells) (Supplementary Fig. 1b,d) affected under these conditions. Taken together, expansion of inflammatory monocytes in the aorta and circulation was selectively associated with the present experimental model and conditions.

TGF $\beta$, a central molecule in the pathogenesis of Marfan aortopathy ${ }^{12,14,32-34}$, and its downstream signalling pathways (canonical pSmad2 (ref. 35) and non-canonical pERK1/2 (ref. 12)) were not affected in either Klff $f^{f / f l}$;LysM Cre mice or heterozygous knockout mice, while pSTAT3, a downstream signalling pathway of IL-6, was activated in both mice (Fig. 4a-d), suggesting that the TGF $\beta$-mediated pathway was not critically involved in the underlying phenotype, and that the IL-6/STAT3 pathway is.

GM-CSF is a downstream target of KLF6. Delineation of target molecules and mechanisms of regulation of immune cells was next addressed using RNA profiling array analysis. Remarkably, $G M-C S F$ levels showed the greatest increase in macrophages derived from bone marrow of $K l f 6^{f l / f l}$;LysM Cre mice in response to AngII stimulation (3.89-fold) as compared with control 
a

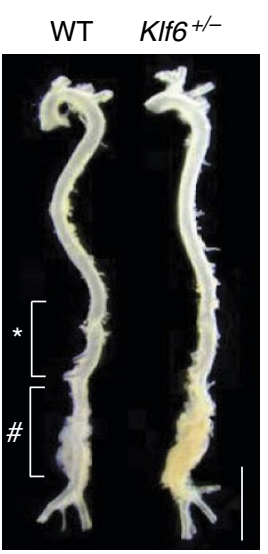

d

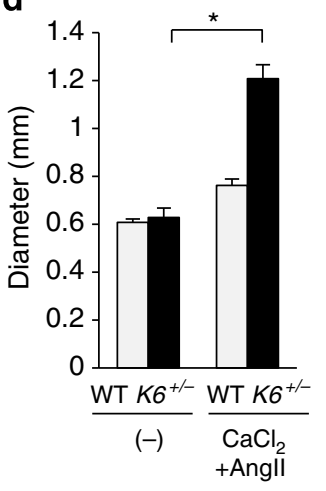

b

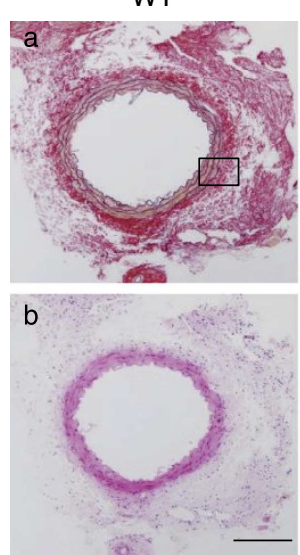

e

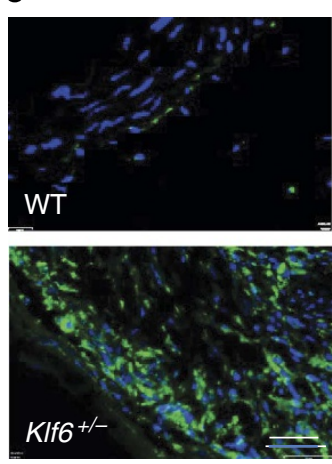

$K l f 6^{+/-}$

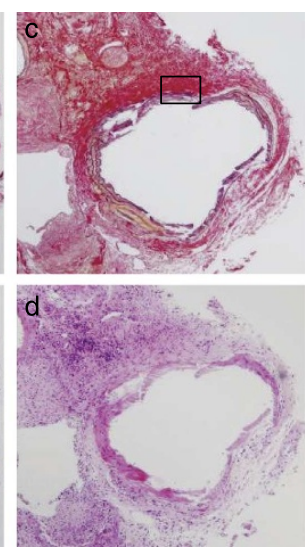

f

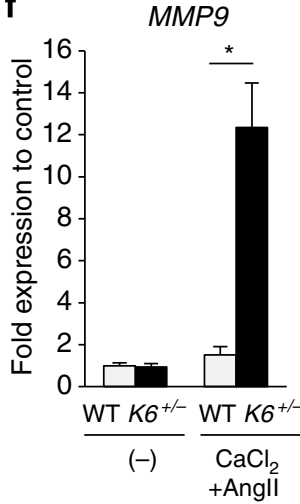

C
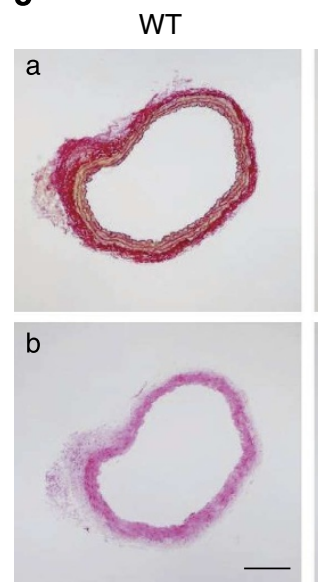

F4/80

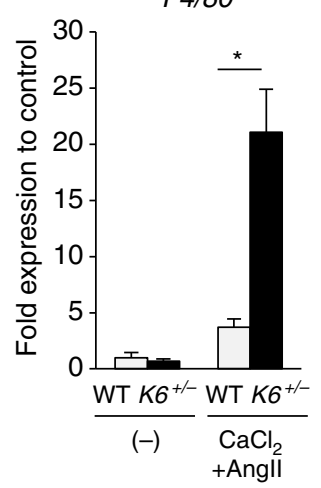

$K_{I f 6}+-$

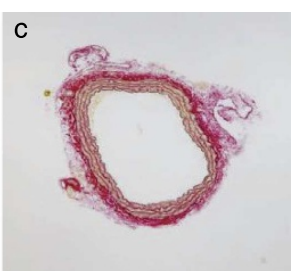

d

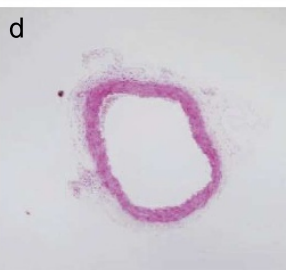

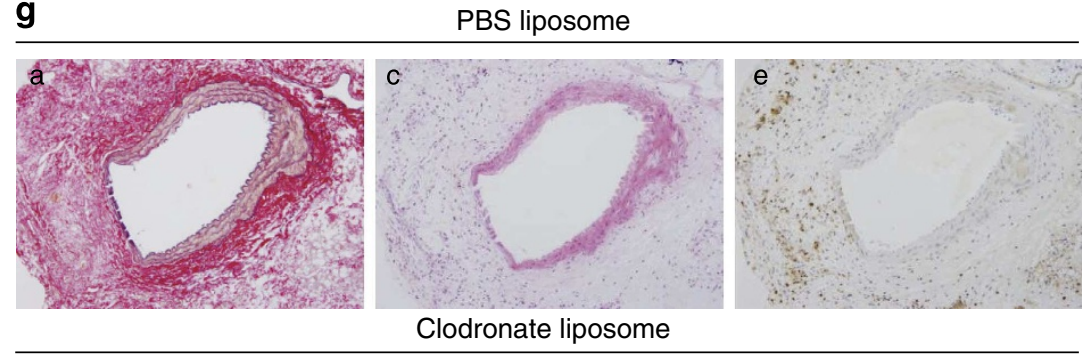
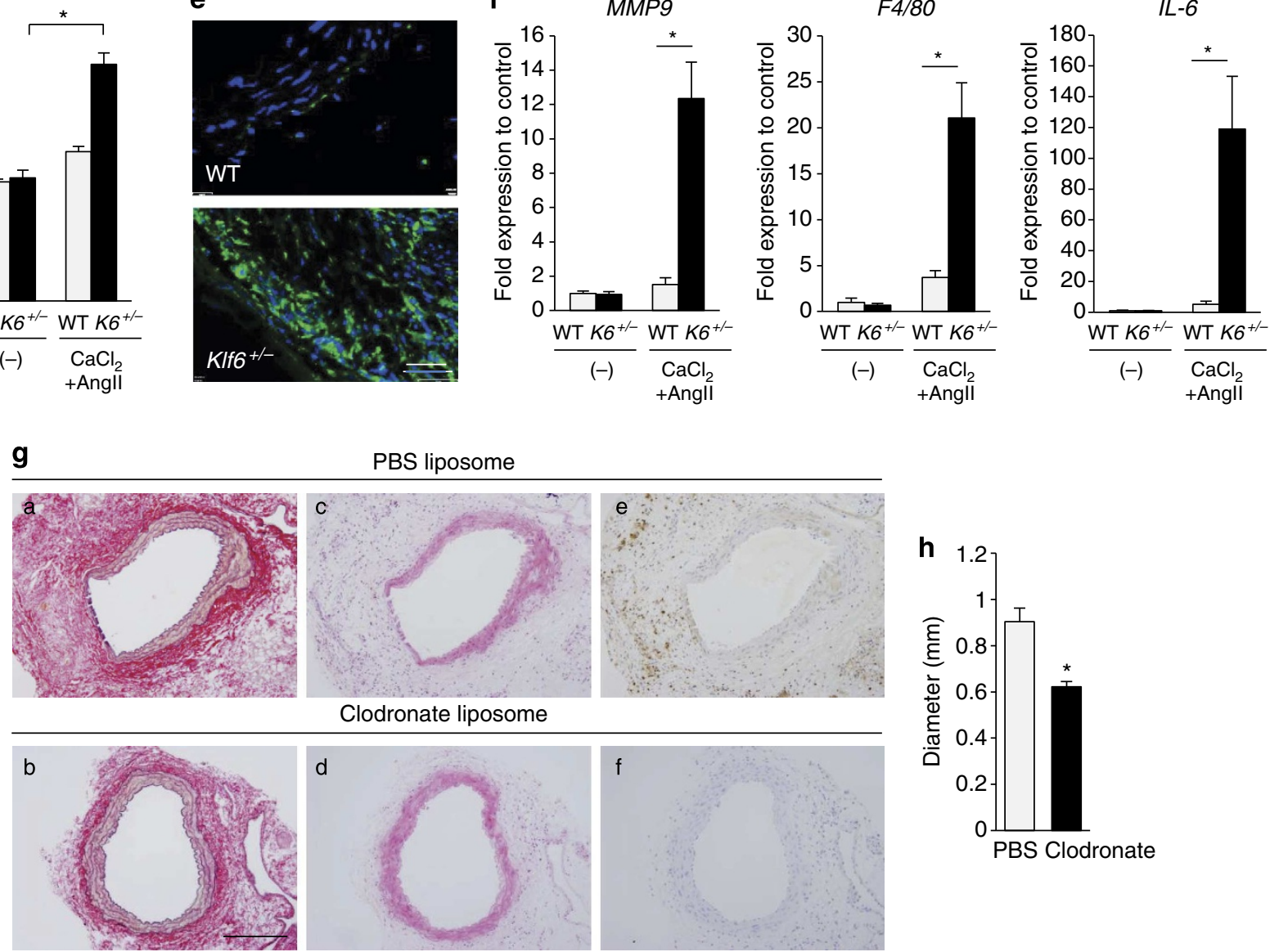

Figure 1 | Aortic aneurysm and inflammation in KIf6 heterozygous knockout mice. (a) Representative aorta (infrarenal aorta: hash, suprarenal aorta: asterisk) induced by 2 weeks of Angll infusion with $\mathrm{CaCl}_{2}$ application in wild-type (WT) littermates $(n=11)$ and Klf6 heterozygous knockout $(K I f 6+/-$, $n=10$ ) mice. Scale bar, $5 \mathrm{~mm}$. Histopathological analysis of infrarenal (b) and suprarenal aorta (c) by EVG (upper panels, a and c) and haematoxylin/eosin (H\&E) staining (lower panels, b and d). Scale bar, $200 \mu \mathrm{m}$. (d) Quantification of infrarenal aortic diameters between WT littermates and Klf6 heterozygous knockout $\left(\mathrm{K}^{+/-}\right)$mice before $((-), n=3)$ and after 2 weeks of Angll infusion with $\mathrm{CaCl}_{2}$ application $\left(\mathrm{CaCl}_{2}+\mathrm{Angll}_{,} \mathrm{WT} ; n=10, K 6^{+/-} ; n=8\right)$. ${ }^{\star} P<0.05$, Student's $t$-test. (e) Immunofluorescent staining for macrophages (green: Mac3, blue: DAPI) in boxed area of EVG-stained aorta (b) of WT littermates and KIf6 heterozygous knockout mice. Scale bar, $30 \mu \mathrm{m}$. (f) Expression of RNA levels of MMP9, F4/80 and IL-6 in aorta from WT littermates and KIf6 heterozygous knockout $\left(\mathrm{K}^{+/}{ }^{-}\right)$mice before $((-), n=3)$ and after Angll infusion with $\mathrm{CaCl}_{2}$ application $\left(\mathrm{CaCl}_{2}+\mathrm{Angll}, n=5\right)$ as examined using real-time PCR and normalized by GAPDH messenger RNA. ${ }^{\star} P<0.05$, Mann-Whitney test. (g) Inhibitory effect of clodronate liposomes on aortic phenotype $(n=4)$ compared with PBS-liposome-administered mice $(n=5)$ by EVG (left panels, a and b); H\&E (middle panels, c and d); and F4/80 staining (right panels, e and f, immunohistochemistry). Scale bar, $200 \mu \mathrm{m}$. (h) Quantification of infrarenal aortic diameters from clodronate-liposome- or PBS-liposome-administered mice ( ${ }^{\star} P<0.05$, Student's $t$-test, $n=4$ or 5 mice per group). Results are from three independent experiments. All values are presented as means \pm s.e.m. 
a

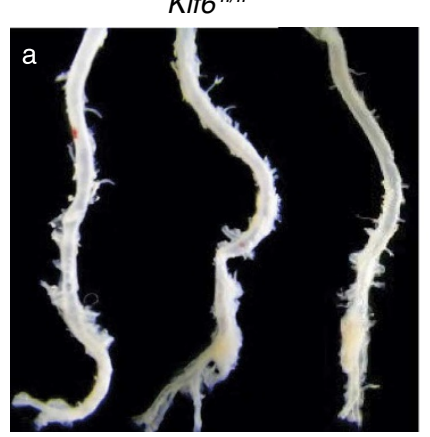

C

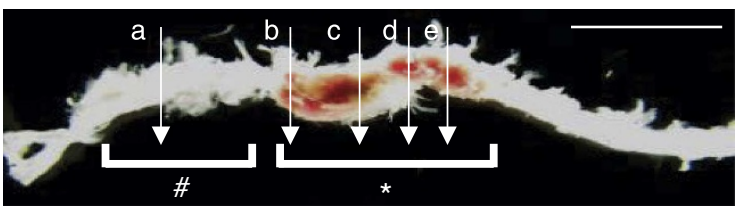

d

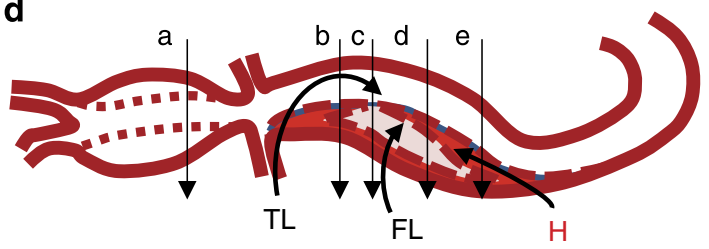

b
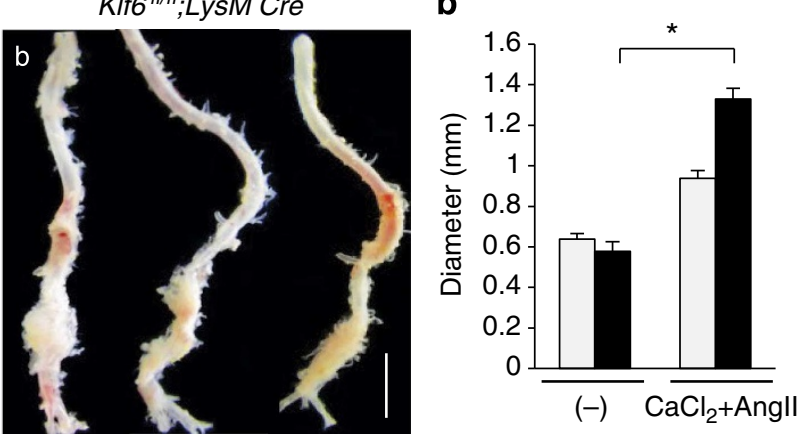

f

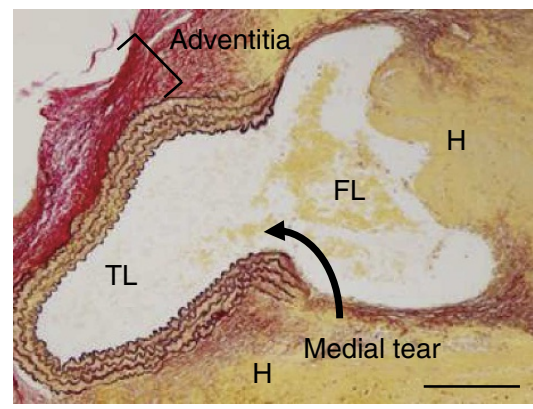

e
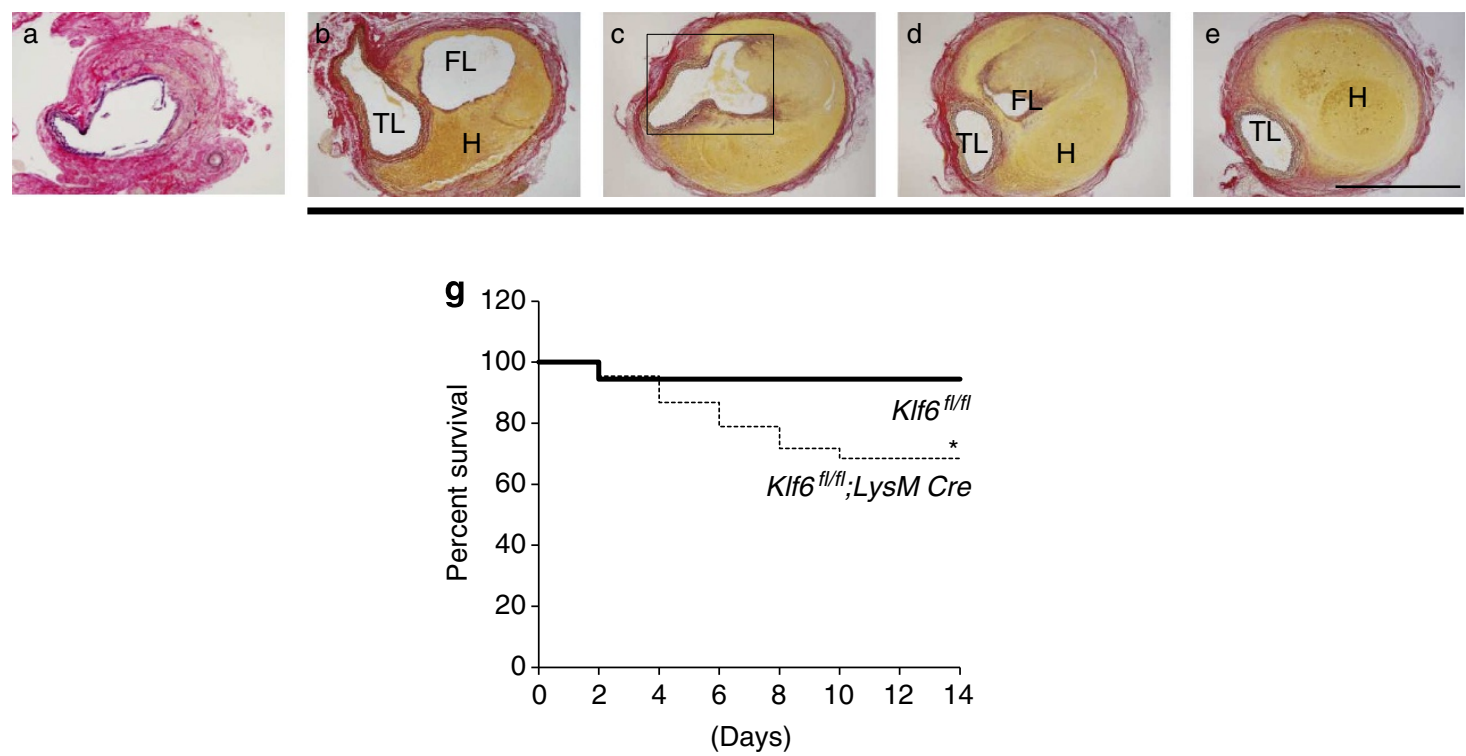

Figure 2 | Myeloid Klf6-deficient mice show aortic dissection/haematoma. (a) Representative aorta of Klff $f^{f / f l}$ control mice (a) and KIff ${ }^{f l / f l ;}$; LysM Cre mice (b) after 2 weeks of Angll infusion with $\mathrm{CaCl}_{2}$ application. Scale bar, $5 \mathrm{~mm}$. (b) Quantification of infrarenal aortic diameters before $((-), n=3)$ and after 2 weeks of Angll infusion with $\mathrm{CaCl}_{2}$ application $\left(\mathrm{CaCl}_{2}+\mathrm{Angll}, n=5\right)$. Results are from three independent experiments. All values are presented as means \pm s.e.m. ${ }^{\star} P<0.05$, Student's $t$-test. (c) Thoracic-abdominal aorta subjected to $\mathrm{CaCl}_{2}$ application and Angll infusion (infrarenal aorta: hash, suprarenal aorta: asterisk). Note that intramural thrombus formation is present in the suprarenal region. Scale bar, $5 \mathrm{~mm}$. (d) Schematic illustration of the diseased aorta (TL: true lumen, FL: false lumen, $\mathrm{H}$ : haematoma). (e) Cross-sectional histological sections stained by Elastica van Gieson. (a) Cross-section of the infrarenal abdominal aorta $\left(\mathrm{CaCl}_{2}\right.$ application region). (b) At the level of the renal arteries. (c) Suprarenal level where the intima-medial layer shows a tear. ( $d$ and e) Suprarenal descending thoracic aorta beyond the intima-medial tear. Scale bar, $1 \mathrm{~mm}$. (f) High-magnification cross-section at the suprarenal level (e(c, boxed)). Intima-medial tear and false lumen/mural thrombus formation are present. Scale bar, $200 \mu \mathrm{m}$. (g) Survival curve between $K I f 6^{f l / f l}$ control mice $(n=19)$ and $K I f 6^{f l / f l}$, LysM Cre mice $(n=22)$ with $\mathrm{CaCl}_{2}$ application and Angll infusion. ${ }^{\star} P<0.05$, log-rank test.

macrophages (Fig. 5a). Macrophages obtained from the aorta of Klf $6^{f l f f} ;$ LysM Cre mice showed markedly increased expression of $G M$-CSF under experimental conditions of $\mathrm{CaCl}_{2}$ application and
AngII infusion (Fig. 5b), and in macrophages derived from bone marrow of these mice (Supplementary Fig. 2a). Expression of $G M-C S F$ in the aorta was elevated from 3 days after treatment 


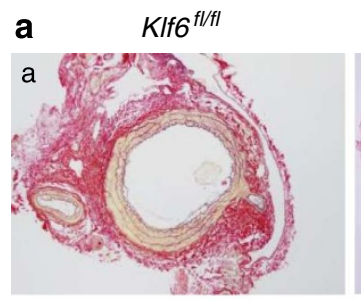

$K_{I f 6^{f l / f l} ; \text { LysM Cre }}$
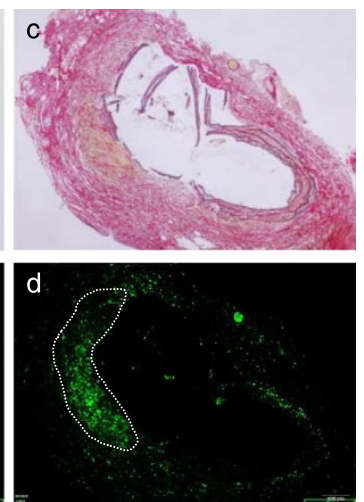

d

C

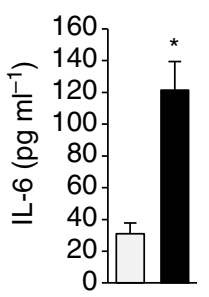

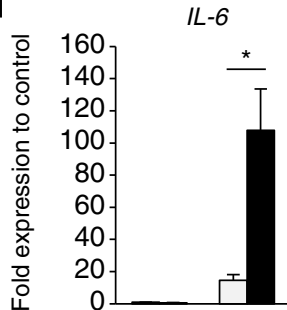

$\overline{(-)} \overline{\mathrm{CaCl}_{2}}+$ Angll b
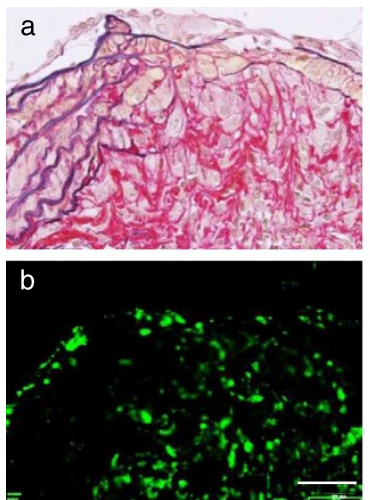

e

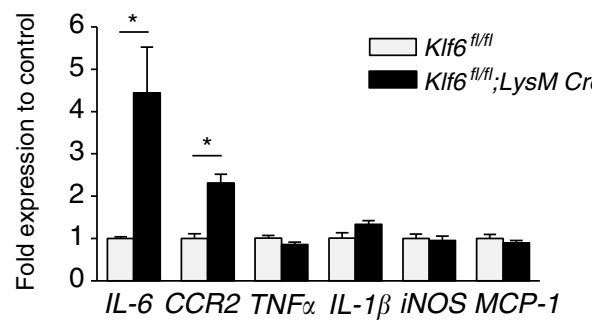

f

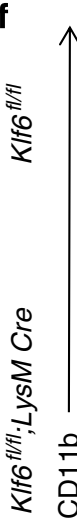

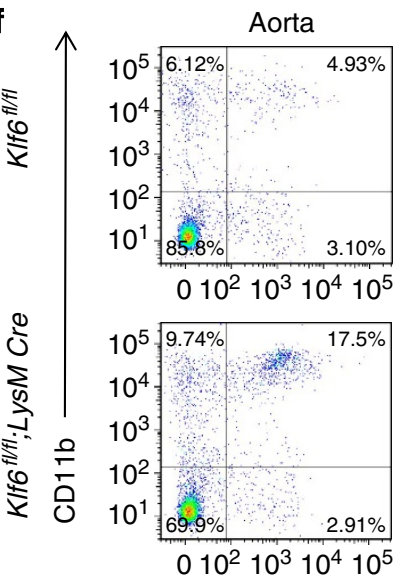

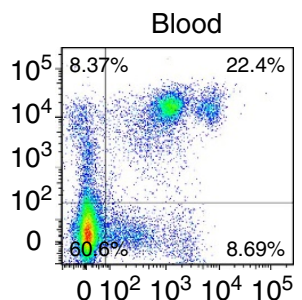
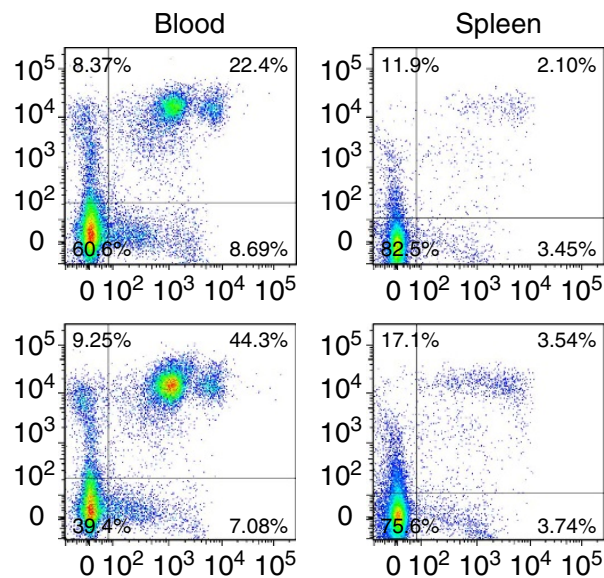
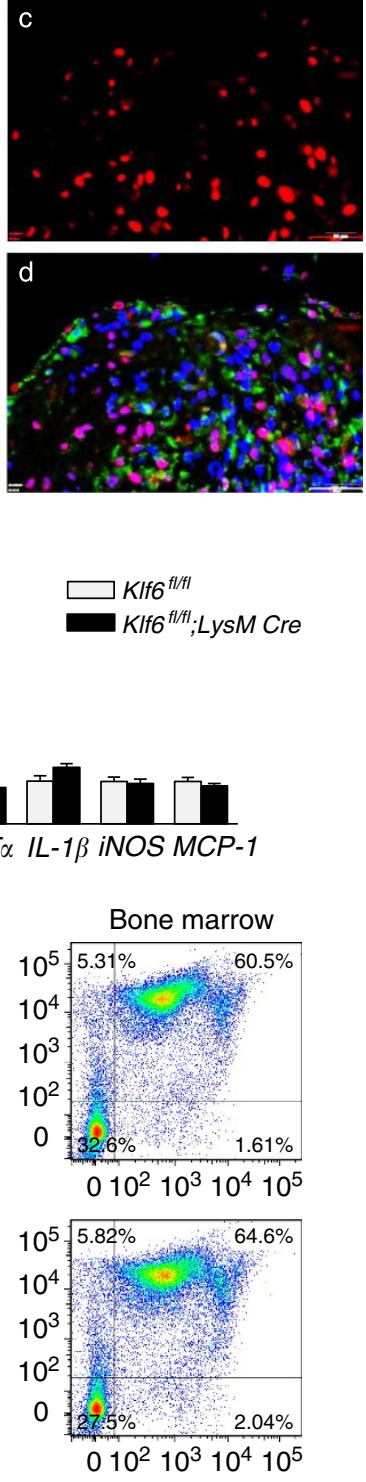

Ly6C

Figure 3 | Marked inflammation in the aortic lesion of myeloid KIf6-deficient mice. (a) Infiltrated macrophages were visualized by immunofluorescent staining (dotted line, green, Mac3) in aorta of KIf6fl/fl; LysM Cre mice (right panels, c and d) compared with KIfffl/fl mice (left panels, a and b). Scale bar, $100 \mu \mathrm{m}$. (b) Immunofluorescent staining for macrophages (b: green, Mac3), pSTAT3 (c: red) and nuclei (d: 4', 6-diamidino-2-phenylindole, blue) in

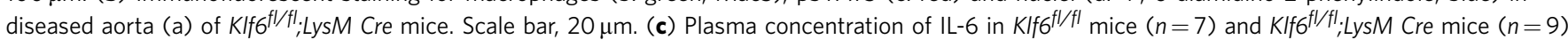
after 2 weeks of Angll infusion with $\mathrm{CaCl}_{2}$ application. ${ }^{\star} P<0.05$, Student's $t$-test. (d) Expression of RNA levels of $I L-6$ were examined in aorta from $K I f 6 f l / f l$ mice and $K I f f^{f / f l}$;LysM Cre mice before $((-), n=3)$ and after 2 weeks of Angll infusion with $\mathrm{CaCl}_{2}$ application $\left(\mathrm{CaCl}_{2}+\mathrm{Angll}, n=5\right)$ using real-time PCR and normalized by GAPDH messenger RNA. (e) Expression of RNA levels of IL-6, CCR2, TNF $\alpha$, IL-1 $\beta$, iNOS and MCP-1 were examined in bone-marrowderived macrophages subjected to Angll stimulation $(10 \mu \mathrm{M})$ for $3 \mathrm{~h}\left(n=3\right.$ mice per group). (f) Population of CD11b ${ }^{+}$Ly6C $C^{\text {hi }}$ cells in aorta, peripheral blood,

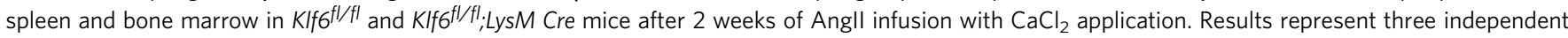
experiments. All values are presented as means \pm s.e.m. ${ }^{\star} P<0.05$, Mann-Whitney test $(\mathbf{d}, \mathbf{e})$.

(before onset of aortic dissection) of $\mathrm{Klf}_{\mathrm{fl}}^{\mathrm{fl} f \mathrm{l}}$;LysM Cre mice (Fig. 5c). Whether deletion of KLF6 in macrophages affects secretion of GM-CSF and further systemic circulating levels was next asked. Macrophages and GM-CSF co-localized in the aorta of $\mathrm{KlfG}^{f l / f l}$;LysM Cre mice, and GM-CSF was markedly produced by macrophages in response to pro-inflammatory stimuli (Fig. $5 \mathrm{~d}$; Supplementary Fig. 2b). Circulating levels of GM-CSF were at least 73.3-fold higher in Klf6-deleted mice (Fig. 5e). It therefore seems that a markedly increased response in GM-CSF is a hallmark feature of the aorta in $K l f 6^{f l f l} ; L y s M$ Cre mice.
We next sought to understand mechanisms underlying regulation of GM-CSF expression and secretion by KLF6. Overexpression of KLF6 significantly attenuated GM-CSF expression induced by pro-inflammatory stimuli in macrophages (Supplementary Fig. 2c). Transcriptionally, several KLF-binding sites were present in the promoter region of GM-CSF to which KLF6 was recruited by agonistic stimuli treatment in macrophages (Supplementary Fig. 2d). These results demonstrated that, mechanistically, GM-CSF is a direct target of KLF6 and that KLF6 represses expression of GM-CSF. 
a

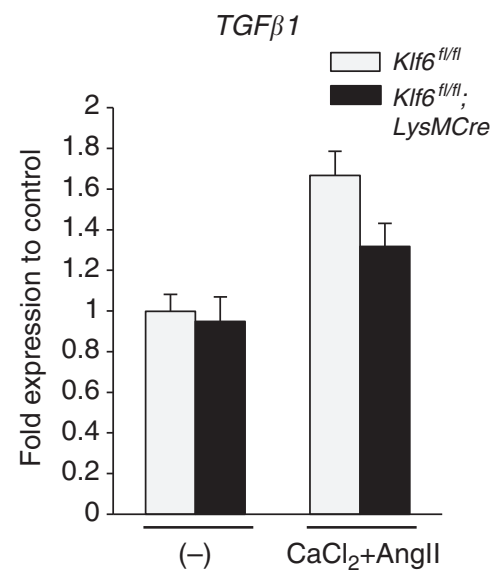

c

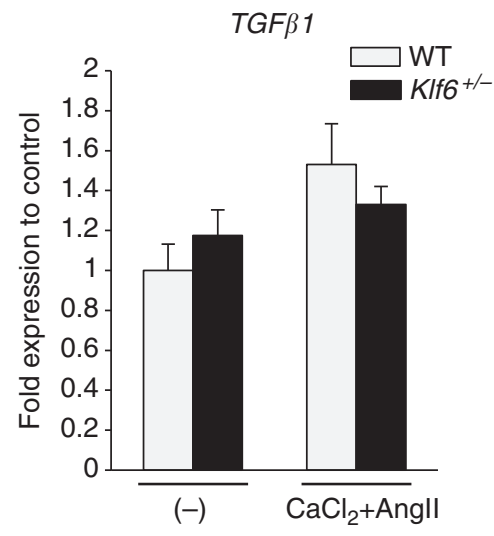

b

\begin{tabular}{|c|c|c|c|}
\hline \multicolumn{2}{|c|}{$(-)$} & \multicolumn{2}{|c|}{$\mathrm{CaCl}_{2}+$ Angll } \\
\hline$K I f \sigma^{f / / f I}$ & $\begin{array}{c}\text { KIff } 6^{\text {fl/fli; }} \\
\text { LysM Cre }\end{array}$ & $K I f 6^{f / f f l}$ & $\begin{array}{l}\text { KIff }{ }^{f / / f l} ; \\
\text { LysM Cre }\end{array}$ \\
\hline 12 & 1 & 2 & 1 \\
\hline
\end{tabular}

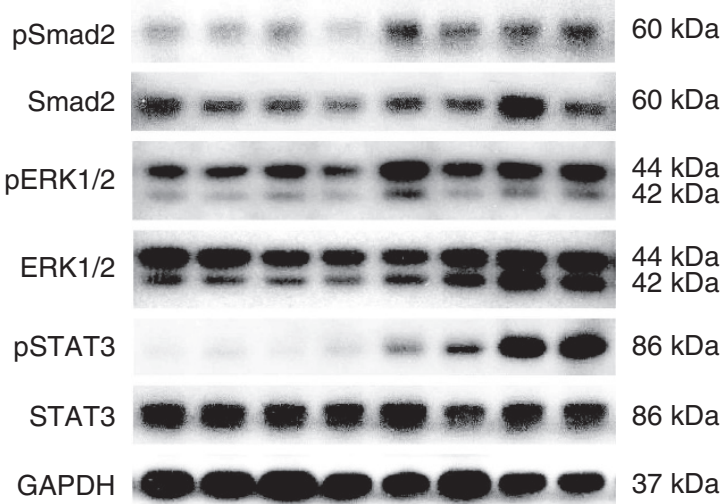

d

$\frac{(-)}{\frac{\mathrm{WT}}{1 \quad 2} \frac{\mathrm{Klf6}^{+-}}{1}} \frac{\mathrm{CaCl}_{2}+\text { Angll }}{\frac{\mathrm{WT}}{1}} \frac{\mathrm{Klf6}^{+/-}}{1 \quad 2}$

pSmad2 $*+\infty-\infty=60 \mathrm{kDa}$

Smad2 $-m-m=60 \mathrm{kDa}$

pERK1/2 $3333034 \mathrm{kDa}$

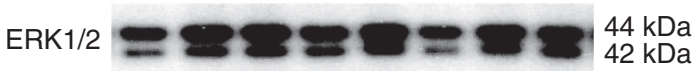

рSTAT3 - - - - - $86 \mathrm{kDa}$

STAT3 00000000000

GAPDH $37 \mathrm{kDa}$

Figure 4 | Involvement of TGF $\beta$ pathways in aortic dissection/haematoma. Expression of messenger RNA (mRNA) levels of TGF $\beta 1$-related factors in aorta from $K I f 6^{f l / f l}$ and $K I f 6^{f l / f l}$ LLySM Cre mice (a), and in wild-type (WT) littermates and $K I f 6^{+/-}$mice (c), using real-time PCR normalized by GAPDH mRNA. $n=5$ per group. All values are presented as mean \pm s.e.m. Western blot analysis for pSmad2, Smad2, pERK1/2, ERK1/2, pSTAT3,

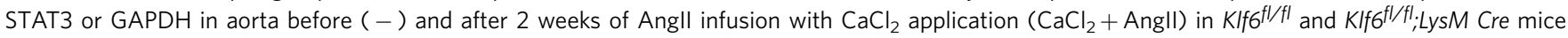
(b) and WT littermates and $\mathrm{KIfG}^{+/-}$mice (d). Results represent three independent experiments.

GM-CSF manipulation regulates aortic dissection/haematoma. To next test the requirement of GM-CSF in aortic dissection in these mice, the actions of GM-CSF were blocked using a neutralizing antibody, which abrogated aortic dissection/intramural haematoma (Fig. 6a,b) as well as expression of GM-CSF receptor $\alpha, M M P 9, F 4 / 80$ and $I L-6$ (Fig. $6 \mathrm{~d}$ ) in addition to serum levels of IL-6 (Fig. 6c). GM-CSF was therefore required for the aortic phenotype in $K l f f^{f l f l}$;LysM Cre mice.

We further investigated whether GM-CSF is sufficient to induce aortopathy. Administration of GM-CSF in wild-type mice subjected to aortic inflammation ( $\mathrm{CaCl}_{2}+$ AngII) caused aortic dissection/ intramural haematoma, confirming the generality of the role of GM-CSF in the pathogenesis of the condition. Mice died from aortic rupture due to the aortic lesion and showed pathological features of the condition (for example, fragile aorta, intimal tear with haematoma) (Fig. 6e-h,j). However, aortic dissection/intramural haematoma did not develop by administration of GM-CSF alone, even with abnormally increased circulating levels (at least 180.9-fold) of GM-CSF (Supplementary Fig. 3a,b). As AngII, $\mathrm{CaCl}_{2}$ or GM-CSF alone was not sufficient to induce the condition, it seems that a combination of aortic inflammation with GM-CSF infusion is necessary for the phenotype (Supplementary Fig. 4a,b). Consistent with this, circulating levels of GM-CSF in mice were only markedly elevated when treated with the combination of measures as compared with each alone (Fig. 6i). Note that these elevated levels were comparable to those in Klff fl fl. $L y s M$ Cre mice, suggesting that highly elevated levels of GM-CSF are required but not sufficient to cause aortic dissection/intramural haematoma (Fig. 5e).

Finally, whether manipulation of GM-CSF affects the number of peripheral leukocytes was examined. With GM-CSF administration, the number of circulating lymphocytes did not change in either the early phase (5 days) or developed phase (14 days) of the model (Supplementary Tables 2 and 3). With respect to neutrophils, the number in peripheral blood was markedly increased in the early phase, but no difference was observed at 14 days of GM-CSF administration. This was similarly seen in the group in which GM-CSF alone was administered, which did not result in the aortic phenotype. While these changes might be due to acute effects by exogenous GM-CSF treatment, this alone 
a

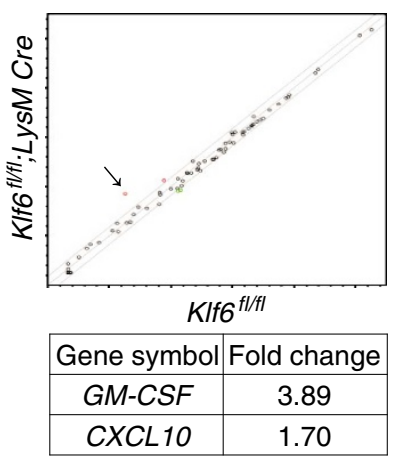

d
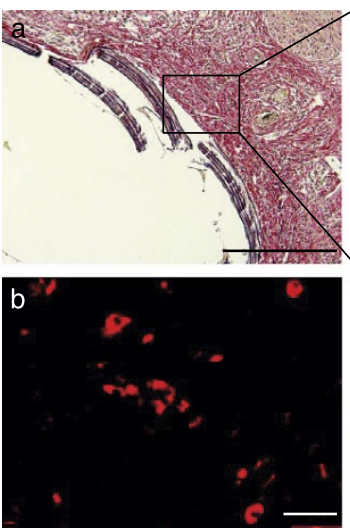

b

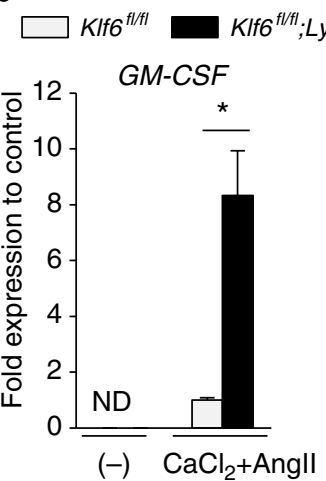

C
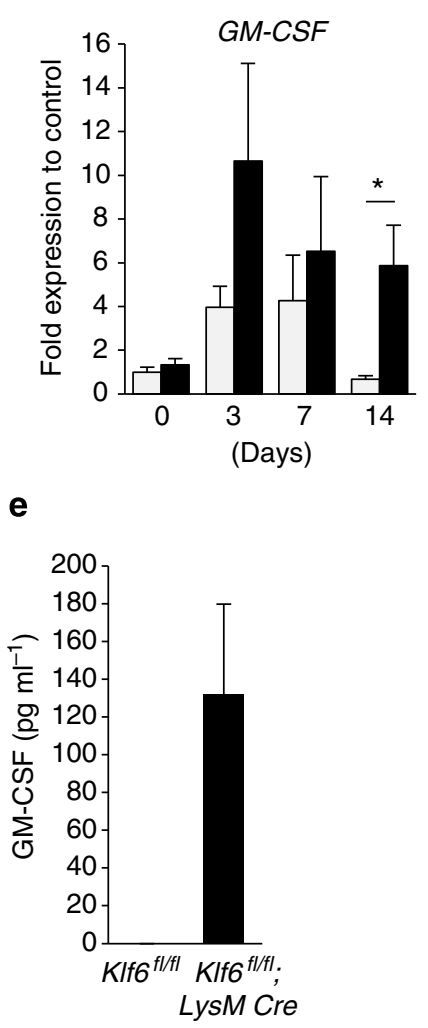

Figure 5 | GM-CSF is a direct target of KLF6 in macrophages. (a) RT2 profiler PCR array analysis of genes related to IL-6/STAT3 inflammatory pathway

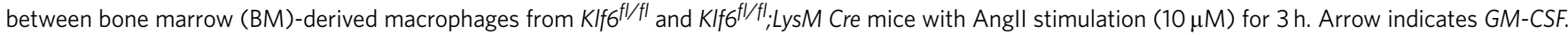
List of genes that showed consistent changes between BM-derived macrophages from KIff $f / / f l$ and $K I f \sigma^{f l} / \mathrm{fl} ; \mathrm{Lys} \mathrm{M}$ Cre mice stimulated with Angll (10 $\mu \mathrm{M}$ ) for $3 \mathrm{~h}$. (b) Messenger RNA (mRNA) expression of GM-CSF in aortic macrophages obtained from KIfffl/fl (sham; $\left(-\right.$ ), $\left.n=3 ; \mathrm{CaCl}_{2}+\mathrm{Angll} ; n=3\right)$ and KIff $6^{f l / f l}$;LysM Cre mice (sham; ( $), n=3 ; \mathrm{CaCl}_{2}+$ Angll; $n=6$ ). ND indicates not detected. (c) mRNA expression of GM-CSF in aorta of KIf6 ${ }^{f l / f l}$ and KIff fl/fl; LysM Cre mice at $\mathrm{O}(n=3), 3(n=3), 7(n=3)$ and $14(n=4)$ days. (d) Immunohistochemistry for macrophages (red: F4/80, b; scale bar, $30 \mu \mathrm{m})$, GM-CSF (green: c) and nucleus (blue: 4', 6-diamidino-2-phenylindole, d) in aorta of KIff fl/fll,LysM Cre mice with EVG-stained infrarenal aorta (a, scale bar,

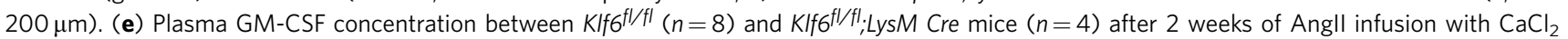
application. Results represent three independent experiments. All values are presented as means \pm s.e.m. ${ }^{\star} P<0.05$, Mann-Whitney test.

had no bearing on the phenotype. Moreover, the number of circulating granulocytes and lymphocytes was not affected when GM-CSF was depleted by the neutralizing antibody (Supplementary Table 4). On the basis of these results, manipulation of GM-CSF did not affect the number of circulating leukocytes in the present model, at least during the observation period (14 days).

Upregulation of GM-CSF in patients with aortic dissection. To confirm the clinical relevance of our findings, circulating levels of GM-CSF were measured in sera of patients with acute aortic dissection, which showed marked increases, in contrast to patients with coronary artery disease, aortic aneurysm or healthy volunteers, which showed markedly lower if not negligible levels (Fig. 7a). Furthermore, inflammatory infiltration $\left(\mathrm{CD} 68^{+}\right.$ monocytes/macrophage) and GM-CSF expression were upregulated and co-localized in dissected aorta (Fig. 7b). Thus, GM-CSF is associated with aortic acute dissection not only in mice but also in human conditions.

\section{Discussion}

The present findings show that GM-CSF is a key regulatory molecule causative of aortic dissection/intramural haematoma in a murine model of the condition and to also be associated with the condition in humans. In mice, modulation of GM-CSF by a neutralizing antibody or exogenous administration, respectively, prevented or induced onset of this phenotype. In humans, elevated serum GM-CSF levels and expression of the cytokine in aortic tissue were seen in patients with aortic dissection.

GM-CSF was a central component of the aortic dissection/ intramural haematoma phenotype in our murine model. Previous studies had suggested a limited role of GM-CSF in the pathogenesis of aortic disease $\mathrm{s}^{36-39}$. For example, mice that lack Smad3 manifested a phenotype of aortic aneurysm formation ${ }^{39}$, and GM-CSF was shown to play a pivotal role in the pathogenesis; however, it was assumed that because smad3 is a downstream target of TGF $\beta$, which is a central molecule associated in Marfan aortopathy, the pathogenic mechanism was limited to this genetic aortopathy. Our findings show that activation of the GM-CSF pathway in a manner independent of the TGF $\beta$-SMAD pathway is sufficient to trigger this condition in a model of inflammatory and degenerative aorta (calcium chloride treatment causes stiffening of the aorta to mimic the condition as seen in atherosclerotic human aortas ${ }^{40}$ ). This model is reflective of aortic dissection/intramural haematoma seen in the elderly adult in humans and should be differentiated from the genetic aortopathy in young patients with Marfan syndrome.. GM-CSF tissue expression had also been shown to be increased in 
a patient presenting with aortic dissection in Cogan's disease ${ }^{41}$, an apparently autoimmune condition that is characterized by recurrent corneal inflammation ${ }^{42}$, which was thought to be an isolated finding.

Effects on other non-macrophage myeloid cells were investigated, which showed that dendritic cells (CD11c ${ }^{+} \mathrm{MHCII}^{+}$cells) were increased in the diseased aorta but not in the circulation under KLF6-deficient conditions, and lack of effects on neutrophils ( $\mathrm{Ly}_{6 \mathrm{G}}{ }^{+}$cells) either in the circulation or in the aortic tissue (Supplementary Fig. 1; Supplementary Fig. 5). The contributory role of non-macrophage myeloid cells (for example, dendritic cells) needs to be further investigated.

Macrophage colony-stimulating factor (M-CSF) has been also suggested to be an important regulator of vascular remodelling 43,44 . Although the precise molecular mechanisms of the actions of M-CSF are still unclear, different actions as a

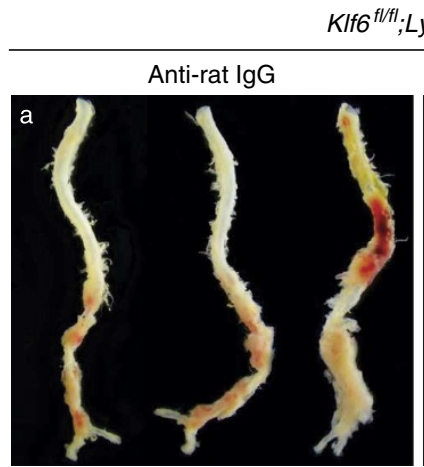

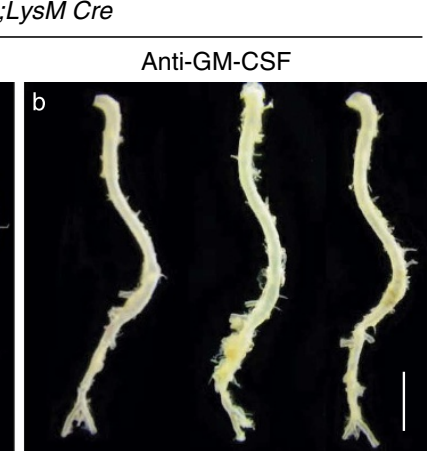

b

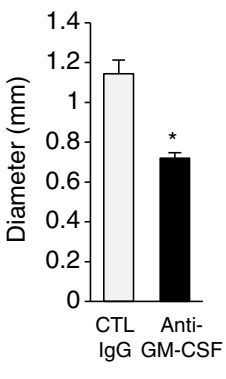

C

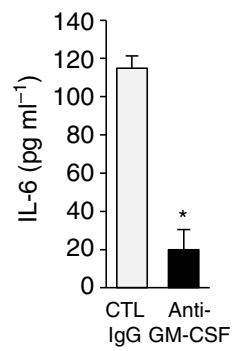

d $\quad G M-C S F R \alpha$

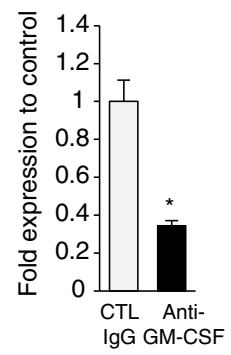

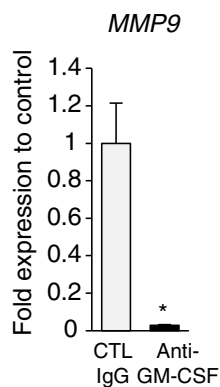
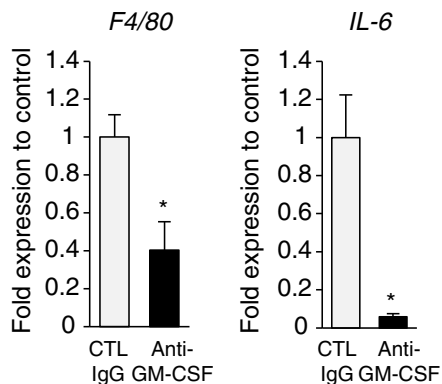

e

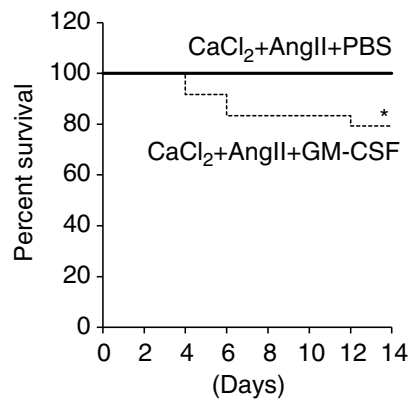

f

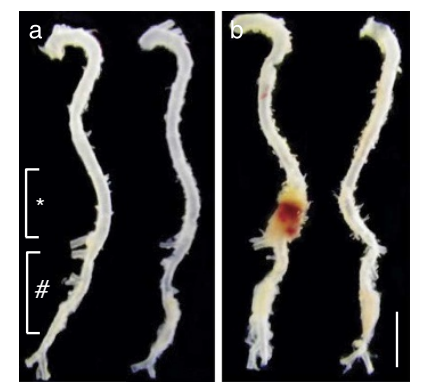

g
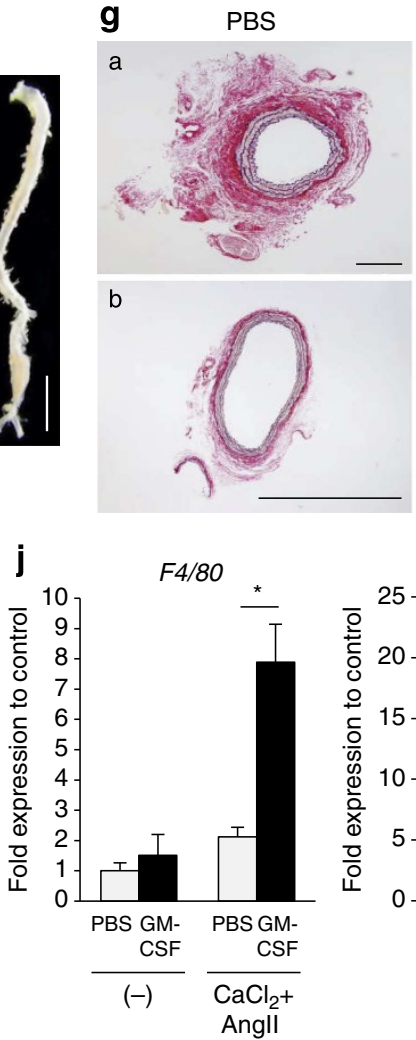

GM-CSF
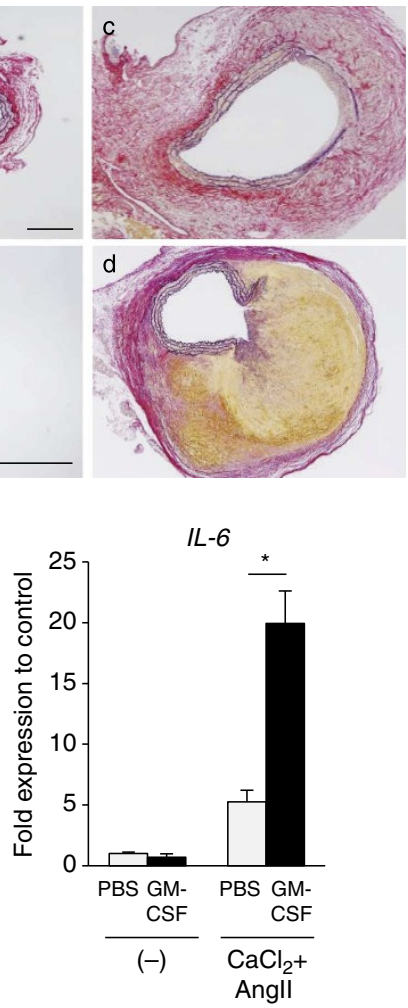

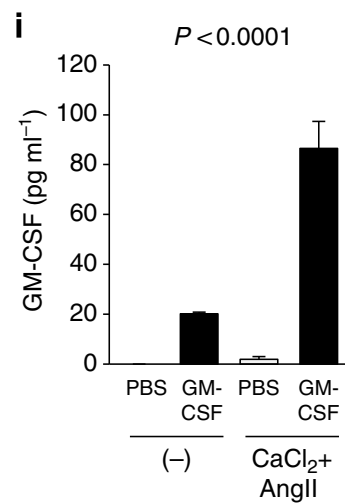


compared with GM-CSF are envisioned, given different expression patterns in the vascular wall. Whereas M-CSF is constitutively expressed under physiological conditions in endothelial cells, fibroblasts, macrophages and smooth muscle cells, GM-CSF, by contrast, is expressed only in minute amounts in these cells under basal conditions, but instead is induced by inflammatory stimuli (for example, tumour necrosis factor) ${ }^{45}$ or oxidized low-density lipoprotein cholesterol stimulation ${ }^{46}$. In murine and human lesions, M-CSF is detected both in healthy arteries and in atherosclerotic lesions associated with macrophage and foam cell content, and is correlated with plaque progression in the latter. By contrast, only minute levels of GM-CSF are seen in smooth muscle cells and endothelial cells of healthy human arteries, but are elevated upon atherosclerotic development and macrophage accumulation ${ }^{47}$. On the basis of these observations, collectively, while M-CSF is a constitutively expressed cytokine in the vasculature, GM-CSF is markedly induced in diseased vessels to regulate pathological conditions including the described aortopathy.

In the experimental model, most previous studies have used AngII infusion alone as an intervention to induce a dissection phenotype ${ }^{16,48}$. However, the limitation of this procedure for mechanistic investigations including inflammation was the low reproducibility (less than 30\%), need for long-term infusion of AngII (more than 4 weeks) and incidence/expression of phenotype in aged mice (over 7-10 months age) with a specific genetic background $\left(a p o E^{-/-}\right.$or $l d l$ receptor $-\%$ mice). Most noteworthy is that the present model could induce aortic dissection/intramural haematoma within 2 weeks with high reproducibility (at least 70\%) even in young wild-type mice. Mechanistically, this model might involve hemodynamic stress on the suprarenal dissection site due to loss of Windkessel effect ${ }^{49}$ because of increased stiffening in the infrarenal aorta (for example, downward shift of the pressure-diameter curve after $\mathrm{CaCl}_{2}$ application with continuous AngII infusion) ${ }^{40}$ that showed aneurysmal formation, which when exposed to inflammatory effects of GM-CSF triggered dissection/intramural haematoma formation in the weak and fragile suprarenal aorta. As aortic aneurysm is commonly co-present in patients with dissection ${ }^{4}$, the described animal model and findings closely resemble the condition seen in patients.

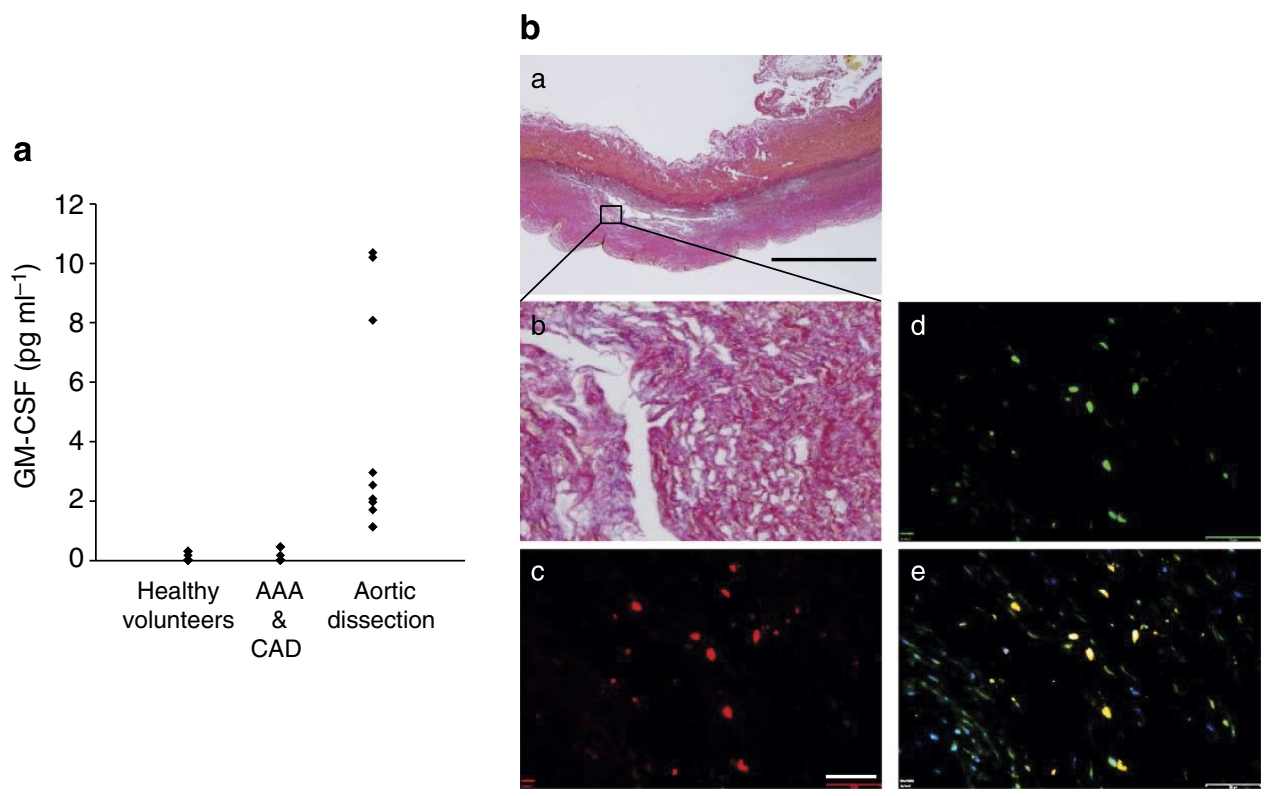

Figure 7 | Increased GM-CSF in patients with acute aortic dissection. (a) Plasma GM-CSF concentration in healthy volunteers ( $n=12)$ and patients with aortic aneurysm (AAA, $n=3)$, coronary artery disease (CAD, $n=11)$ or aortic dissection $(n=10)$. (b) Immunofluorescent staining for CD68 (red, c, scale bar, $50 \mu \mathrm{m}$ ), GM-CSF (green, d) and 4',6-diamidino-2-phenylindole (blue, e) in descending dissected aorta (boxed area, a, scale bar, 2 mm) with EVG staining (b). Results represent three independent experiments.

Figure 6 | GM-CSF is required for aortic dissection/intramural haematoma. (a) Representative aortas of Klff ${ }^{f / / f l}$; LysM Cre mice with administration of anti-GM-CSF neutralizing antibody ( $b$, anti-GM-CSF, $n=8$ ) or control IgG antibody $(a, n=10)$ after 2 weeks of Angll infusion with $\mathrm{CaCl}_{2}$ application. Scale bar, $5 \mathrm{~mm}$. Quantification of infrarenal aortic diameters (b, anti-GM-SCF: $n=7$; anti-control IgG: $n=9$ ) and plasma concentration of IL-6 (c, $n=5$ or 6 ) between anti-GM-CSF antibody-administered and anti-control IgG-administered mice. ${ }^{\star} P<0.05$, Student's $t$-test. (d) Expression levels of RNA of GM-CSFR $\alpha$, MMP9, F4/80 and IL-6 were examined in aorta of anti-GM-CSF antibody-administered mice or anti-control lgG-administered mice using real-time PCR and then normalized by GAPDH messenger RNA (mRNA) ( $n=5$ mice per group). (e) Survival curve of mice with administration of recombinant GM-CSF $(n=26)$ or PBS $(n=19)$ with $\mathrm{CaCl}_{2}$ application and Angll infusion in wild-type mice. ${ }^{\star} P<0.05$, log-rank test. (f) Representative aorta of wild-type mice with administration of recombinant GM-CSF (b) or PBS (a) with $\mathrm{CaCl}_{2}$ application and Angll infusion (infrarenal aorta: hash, suprarenal aorta: asterisk) for 4 weeks. Scale bar, $5 \mathrm{~mm}$. (g) Histopathological analysis of infrarenal aorta (upper panels: a and c, scale bar, $200 \mu \mathrm{m}$ ) and suprarenal aorta (lower panels: b and d, scale bar, $1 \mathrm{~mm}$ ) by EVG staining. (h) Quantification of infrarenal aortic diameters between recombinant GM-CSFadministered mice or PBS-administered mice (sham; ( -$), n=3, \mathrm{CaCl}_{2}+$ Angll; $n=5$ ). (i) Plasma GM-CSF concentration after 2 weeks infusion of recombinant GM-CSF or PBS with or without $\mathrm{CaCl}_{2}$ application and Angll infusion ( $n=3 \sim 5$ mice per group). (j) Expression levels of RNA of $F 4 / 80$ and IL6 were examined in aorta from mice administered recombinant GM-CSF or PBS using real-time PCR and then normalized with GAPDH mRNA (sham; ( - ), $n=3, \mathrm{CaCl}_{2}+$ Angll; $n=5$ ). Results are from three independent experiments. All values are presented as means \pm s.e.m. ${ }^{\star} P<0.05, M a n n-W h i t n e y$ test $(\mathbf{d}, \mathbf{h}, \mathbf{j})$ and one-way analysis of variance with Dunn's post-test (i). 
Taken together, our findings suggest that GM-CSF is a central regulator of aortic dissection/intramural haematoma in the atherosclerotic and inflammatory aorta, which is typically seen in the elderly patient with this condition, and may serve as a potential target for diagnostic and therapeutic exploitation (for example, aortic stabilization using GM-CSF antagonists), as well as a diagnostic biomarker.

\section{Methods}

Mice. Heterozygous $\mathrm{Klf6}^{+/-}$mice (C57BL/6) were originally generated by Tarocchi et al. ${ }^{50}$ To generate macrophage-specific Klf6-knockout mice, Klf $6 \mathrm{fl} / \mathrm{ll}$ mice (C57BL/6;129Sv) were cross-bred with LysM Cre mice (C57BL/6, Jackson laboratory $)^{51}$. Only male mice, 10 - to 13 -weeks of age, and C57BL/6 as wild-type mouse (CLEA Japan) were used. All experimental protocols were approved by the Ethics Committee for Animal Experimentation at the Graduate School of Medicine, the University of Tokyo, and conducted in accordance with the Guidelines for the Care and Use of Laboratory Animals of the Department of Medicine, the University of Tokyo.

Murine aortic dissection/intramural haematoma model. To induce aortic dissection/intramural haematoma, peri-aortic application of $\mathrm{CaCl}_{2}$ was performed on the abdominal aorta, followed by a 2-week infusion of AngII (2,000 $\mathrm{ng} \mathrm{kg}^{-1}$ $\left.\mathrm{min}^{-1}\right)^{40}$. In detail, mice were anaesthetized and underwent laparotomy at $10-13$ weeks of age. The abdominal aorta between the renal arteries and bifurcation of the iliac arteries was isolated from the surrounding retroperitoneal structure, and $0.5 \mathrm{M}$ $\mathrm{CaCl}_{2}$ was applied to the external surface of the infrarenal aorta. $\mathrm{NaCl}(0.9 \%)$ was substituted for $\mathrm{CaCl}_{2}$ in sham control mice. The aorta was rinsed with $0.9 \%$ sterile saline after $15 \mathrm{~min}$ and the incision was closed.

Macrophage depletion and manipulation of GM-CSF. Wild-type mice were injected intraperitoneally with $110 \mathrm{mg} \mathrm{kg}^{-1}$ of clodronate liposomes or equal volume of PBS liposomes 2 days prior and 7 days after induction of aortic dissection. Neutralizing antibody against GM-CSF (300 $\mu \mathrm{g}$, R\&D systems) or control anti-rat IgG antibody (Equitech Bio) was administered every other day by intraperitoneal injection. Recombinant murine GM-CSF $(10,50$ and $100 \mu \mathrm{g} \mathrm{kg}$ per day, PeproTech) was administered for 2 or 4 weeks after induction of aortic dissection.

Histological analysis and immunohistochemistry. Aortas from mice were embedded in paraffin and then $5-\mu \mathrm{m}$-thick serial sections were prepared for Elastic Van Gienson (EVG) and haematoxylin/eosin staining. Digital images of EVG-stained aortas with a reference scale were used for absolute measurement of diameter. Human aortic tissue was obtained from patients undergoing surgical aortic repair with informed consent under a protocol approved by the University of Tokyo Hospital Research Ethics Committee. Paraffin-embedded sections were taken from the aorta for EVG staining and immunohistochemistry. For immunohistochemistry, after deparaffinization and blocking, serial sections were incubated with the following antibodies: Mac3 (dilution 1:200; rat; BD Pharmingen) or F4/80 (1:100; rat; Serotec) for macrophages in mice and CD68 (1:50; mouse; Dako) in humans and GM-CSF (1:100, rabbit; Abcam for mouse and 1:50; rabbit; Acris for humans) or pSTAT3 (1:200; rabbit; Cell Signaling Technology), followed by biotinylated secondary antibodies (1:200; Dako). For detection, anti-streptavidin-conjugated AlexFluor 488 or AlexFluor 594 (1:200; Invitrogen) was used. The nuclei were stained with $4^{\prime}, 6$-diamidino-2-phenylindole (1:5,000; Sigma-Aldrich) after the final series of washes.

Cell preparation from aorta, spleen, bone marrow and blood. Aortas were minced into 3- to $4-\mathrm{mm}$ pieces and placed in $1 \mathrm{ml}$ digestion solution containing collagenase type II $\left(1.25 \mathrm{mg} \mathrm{ml}^{-1}\right.$, Worthington) and porcine pancreatic elastase $\left(50 \mu \mathrm{g} \mathrm{ml}^{-1}\right.$, Worthington) in a base solution of Accumax (Innovative Cell Technologies). Aortic tissue was digested at room temperature with agitation for $1 \mathrm{~h}$. After digestion, cells were washed in FACS buffer (5\% FCS in PBS) at 2,000 r.p.m. for $5 \mathrm{~min}$ (ref. 16). Aortic macrophages were isolated using CD11b microbeads according to the manufacturer's instructions (Miltenyi Biotec). Spleen was homogenized and passed through a cell strainer to obtain single-cell suspensions. Bone-marrow-derived cells were taken from the femur and tibia of 5-6-week-old mice. Blood was collected in heparin-coated vials and then $1.2 \%$ dextran was added for $45 \mathrm{~min}$ at room temperature. Counting of peripheral leukocytes was done by an automated hematology analyzer (XT-2,000i, Sysmex). Neutrophils were isolated from bone marrow using a neurophil isolation kit according to the manufacturer's instructions (Miltenyi Biotec). From single-cell suspensions of spleen, bone marrow and blood, erythrocytes were lysed using ACK lysis buffer for 5, 3 and 2 min on ice, respectively. Cells were centrifuged at 2,000 r.p.m. for $5 \mathrm{~min}$ to remove the ACK lysis buffer, then the single-cell suspensions were resuspended and washed in FACS buffer, followed by centrifugation at 2,000 r.p.m. for $5 \mathrm{~min}$.
Cell cultures. Bone-marrow-derived cells were prepared from femur and tibia of $\mathrm{Klf}^{f l / f l}$ mice or Klf $\mathrm{f}^{f l f l} ; \mathrm{LysM}$ Cre mice to assess the role of GM-CSF in macrophages. KLF6 overexpression was induced by a retrovirus construct for KLF6 (pMXs-KLF6) in the presence of RetroNectin $\left(5 \mu \mathrm{g} \mathrm{cm}^{-2}\right.$, Takara Bio.).

Flow cytometry. Murine $\mathrm{Fc}$ receptors were blocked using antibodies against murine CD16/32 antigens (eBioscience) for $15 \mathrm{~min}$ on ice, after which cells were washed and then resuspended in $100 \mu \mathrm{l}$ FACS buffer. Fluorochrome-conjugated antibodies (all from BioLegend) for APC-CD11b[M1/70], PerCP-Cy5.5-Ly6c[HK1.4], APC-Cy7-Ly6G[1A8] or APC-CD11c[N418] were added for 30-45 min at room temperature. FITC-CD3e[145-2C11], FITC-Ly6G[RB6-8C5], FITCCD11b[M1/70], FITC-CD45R/B220[RA3-6B2] and FITC-Ly76[Ter-119] (erythroid lineage marker) were used as lineage markers. Corresponding isotype control antibodies were added to samples at the same concentrations as the antibodies of interest. After incubation, samples were washed three times and analysed by FACSverse (BD Pharmingen). Compensation was done using positive samples containing single-colour-stained aortic macrophages. Debris and dead cells, as defined by low forward scatter, were excluded from analysis. Data were analysed with FlowJo (Tree Star) (ref. 16).

Chromatin immunoprecipitation. Chromatin immunoprecipitation analysis was performed using a Chromatin Immunoprecipitation Kit (Active Motif) according to the manufacturer's instructions. Briefly, bone-marrow-derived macrophages were stimulated with or without AngII $(10 \mu \mathrm{M}), \mathrm{TNF} \alpha\left(10 \mathrm{ng} \mathrm{ml}^{-1}\right)$ and IL-1 $\beta$ $\left(20 \mathrm{ng} \mathrm{ml}^{-1}\right)$ for $3 \mathrm{~h}$ prior to crosslinking for $10 \mathrm{~min}$ with $1 \%$ formaldehyde. Chromatin was sheared by sonication to an average size of $200 \sim 1,000$ base pairs (Covaris). Immunoprecipitation was performed using anti-KLF6 antibody ( $25 \mathrm{ng} \mathrm{\mu l}^{-1}$, Santa Cruz Biotechnology) and rabbit IgG antibody $\left(25 \mathrm{ng} \mathrm{\mu l}^{-1}\right.$, Santa Cruz Biotechnology). PCR amplification of the GM-CSF promoter region spanning KLF-binding elements was performed using the following primers: forward: $5^{\prime}$-AAGC CCTTCCAAGAACTGGC- ${ }^{\prime}$ and reverse $5^{\prime}$-GGCCCCTCAAA AAGGAGAGG-3'. KLF6 recruitment was normalized by input DNA and compared with the control group using KLF6 antibody.

RNA isolation and quantitative real-time PCR. Total RNA from cultured cells, aortic macrophages, bone-marrow-derived neutrophils or murine aortic samples was extracted using either the RNeasy minikit (Qiagen) or RNAlater (Qiagen) according to the manufacturer's instructions. In total, 0.5-1 $\mu \mathrm{g}$ RNA was reversetranscribed using Superscript III (Invitrogen) according to the manufacturer's instructions. Real-time PCRs were performed using $2 \mu \mathrm{l}$ of resulting cDNA per $20-\mu l$ reaction volume containing SYBR green I master (Roche). Glyceraldehyde 3 -phosphate dehydrogenase was used as an internal control. Using bone-marrowderived macrophages with AngII $(10 \mu \mathrm{M}, 3 \mathrm{~h})$ stimulation, RT2 profiler PCR array (Qiagen) was performed with 84 related genes for the IL-6/STAT inflammatory pathway. PCR was performed on a LightCycler 480 Real-time PCR system (Roche) in accordance with the manufacturer's recommended procedure. Real-time PCR primers are shown in Supplementary Table 5.

Western blot analysis. Mouse aortic specimens were homogenized with lysis buffer (T-PER, Thermo Scientific) containing the protease inhibitor complex (Roche) and phosphatase inhibitors (Roche). Protein concentration was assayed using the BCA protein assay kit (Pierce), and $5 \mu \mathrm{g}$ of the protein were resolved by $10 \%$ NuPAGE (Invitrogen) and then transferred to polyvinylidene difluoride membrane. The blot was probed with primary antibodies: $\mathrm{pS}$ mad2 (dilution 1:400), pERK1/2 (1:3,000), pSTAT3 (1:3,000), Smad2 $(1: 1,000)$, ERK1/2 $(1: 3,000)$ or STAT3 $(1: 3,000)$ (all rabbit antibodies obtained from Cell Signaling Technology) and anti-GAPDH antibody (1:1,000, Ambion). Membranes were washed and incubated with the corresponding horseradish peroxidase-conjugated secondary antibody (Cell Signaling Technology). Protein bands were detected by ECLplus (Thermo scientific) and GAPDH served as an internal control for protein loading. The original blots for the representative images are displayed in Supplementary Fig. 6.

Enzyme-linked immunosorbent assay. Plasma levels of IL-6, MCP-1 and GM-CSF in mice or in humans with or without aortic dissection/intramural haematoma were assayed with commercially available quantikine ELISA kits (R\&D systems) according to the manufacturer's instructions. Sera of healthy volunteers and of patients with aortic aneurysm, coronary artery disease or with aortic dissection were obtained with informed consent under a protocol approved by the University of Tokyo Hospital Research Ethics Committee. Baseline characteristics of human subjects are shown in Supplementary Table 6.

Statistical analyses. All data are presented as means \pm s.e.m. Statistical difference between two groups was determined using the Student's $t$-test (two-tailed) for parametric data or the Mann-Whitney test for non-parametric data after testing for normality by F-test analysis. For data containing multiple time points, two group comparisons at the same time point were done. When comparing multiple 
groups, data were analysed by the Kruskal-Wallis non-parametric one-way analysis of variance with Dunn's post-test. Survival curves were created using the Kaplan-Meier method and compared by a log-rank test. Statistical power for mouse experiments was calculated using Biomath (biomath.info/power). All samples sizes were equal to or greater than the recommended minimum group size. All data were analysed using Prism 6.0 (GraphPad Software). A $P$ value of less than 0.05 was considered significant.

\section{References}

1. Nienaber, C. A. \& Powell, J. T. Management of acute aortic syndromes. Eur. Heart J. 33, 26-35b (2012).

2. Tsai, T. T., Nienaber, C. A. \& Eagle, K. A. Acute aortic syndromes. Circulation 112, 3802-3813 (2005).

3. Hiratzka, L. F. et al. 2010 ACCF/AHA/AATS/ACR/ASA/SCA/SCAI/SIR/STS/ SVM guidelines for the diagnosis and management of patients with thoracic aortic disease. A Report of the American College of Cardiology Foundation/ American Heart Association Task Force on Practice Guidelines, American Association for Thoracic Surgery, American College of Radiology, American Stroke Association, Society of Cardiovascular Anesthesiologists, Society for Cardiovascular Angiography and Interventions, Society of Interventional Radiology, Society of Thoracic Surgeons, and Society for Vascular Medicine. J. Am. Coll. Cardiol. 55, e27-e129 (2010).

4. Hagan, P. G. et al. The International Registry of Acute Aortic Dissection (IRAD): new insights into an old disease. JAMA 283, 897-903 (2000).

5. Suzuki, T. et al. Biomarkers of aortic diseases. Am. Heart J. 165, 15-25 (2013).

6. Suzuki, T., Distante, A. \& Eagle, K. Biomarker-assisted diagnosis of acute aortic dissection: how far we have come and what to expect. Curr. Opin. Cardiol. 25, 541-545 (2010)

7. Clough, R. E. \& Nienaber, C. A. Management of acute aortic syndrome. Nat. Rev. Cardiol. 12, 103-114 (2014).

8. Song, J. K. Aortic intramural hematoma: aspects of pathogenesis 2011. Herz 36, 488-497 (2011)

9. von Kodolitsch, Y. et al. Intramural hematoma of the aorta: predictors of progression to dissection and rupture. Circulation 107, 1158-1163 (2003)

10. Milewicz, D. M., Regalado, E. S. \& Guo, D. C. Treatment guidelines for thoracic aortic aneurysms and dissections based on the underlying causative gene. J. Thorac Cardiovasc. Surg. 140, S2-S4 discussion S45-51 (2010).

11. Milewicz, D. M. et al. Genetic basis of thoracic aortic aneurysms and dissections: focus on smooth muscle cell contractile dysfunction. Annu. Rev. Genomics Hum. Genet. 9, 283-302 (2008).

12. Holm, T. M. et al. Noncanonical TGFbeta signaling contributes to aortic aneurysm progression in Marfan syndrome mice. Science 332, 358-361 (2011).

13. Li, W. et al. Tgfbr2 disruption in postnatal smooth muscle impairs aortic wall homeostasis. J. Clin. Invest. 124, 755-767 (2014).

14. Dietz, H. C. TGF-beta in the pathogenesis and prevention of disease: a matter of aneurysmic proportions. J. Clin. Invest. 120, 403-407 (2010).

15. Ju, X. et al. Interleukin-6-signal transducer and activator of transcription-3 signaling mediates aortic dissections induced by angiotensin II via the T-helper lymphocyte 17-interleukin 17 axis in C57BL/6 mice. Arterioscler. Thromb. Vasc. Biol. 33, 1612-1621 (2013).

16. Tieu, B. C. et al. An adventitial IL-6/MCP1 amplification loop accelerates macrophage-mediated vascular inflammation leading to aortic dissection in mice. J. Clin. Invest. 119, 3637-3651 (2009).

17. Date, D. et al. Kruppel-like transcription factor 6 regulates inflammatory macrophage polarization. J. Biol. Chem. 289, 10318-10329 (2014).

18. Starkel, P. et al. Oxidative stress, KLF6 and transforming growth factor-beta up-regulation differentiate non-alcoholic steatohepatitis progressing to fibrosis from uncomplicated steatosis in rats. J. Hepatol. 39, 538-546 (2003).

19. Holian, J. et al. Role of Kruppel-like factor 6 in transforming growth factorbetal-induced epithelial-mesenchymal transition of proximal tubule cells. Am. J. Physiol. Renal Physiol. 295, F1388-F1396 (2008).

20. Hamilton, J. A. \& Anderson, G. P. GM-CSF biology. Growth Factors 22, 225-231 (2004)

21. Daugherty, A., Manning, M. W. \& Cassis, L. A. Angiotensin II promotes atherosclerotic lesions and aneurysms in apolipoprotein E-deficient mice. J. Clin. Invest. 105, 1605-1612 (2000).

22. Johnston, K. W. et al. Suggested standards for reporting on arterial aneurysms. Subcommittee on Reporting Standards for Arterial Aneurysms, Ad Hoc Committee on Reporting Standards, Society for Vascular Surgery and North American Chapter, International Society for Cardiovascular Surgery. J. Vasc. Surg. 13, 452-458 (1991).

23. Nagasawa, A. et al. Important role of the angiotensin II pathway in producing matrix metalloproteinase-9 in human thoracic aortic aneurysms. J. Surg. Res. 183, 472-477 (2013).

24. Ezekowitz, R. A. \& Gordon, S. Down-regulation of mannosyl receptormediated endocytosis and antigen F4/80 in bacillus Calmette-Guerin-activated mouse macrophages. Role of T lymphocytes and lymphokines. J. Exp. Med. 155, 1623-1637 (1982).
25. Ezekowitz, R. A., Austyn, J., Stahl, P. D. \& Gordon, S. Surface properties of bacillus Calmette-Guerin-activated mouse macrophages. Reduced expression of mannose-specific endocytosis, Fc receptors, and antigen F4/80 accompanies induction of Ia. J. Exp. Med. 154, 60-76 (1981).

26. Atreya, R. et al. Blockade of interleukin 6 trans signaling suppresses T-cell resistance against apoptosis in chronic intestinal inflammation: evidence in crohn disease and experimental colitis in vivo. Nat. Med. 6, 583-588 (2000).

27. Cheuk, B. L. \& Cheng, S. W. Can local secretion of prostaglandin E2, thromboxane B2, and interleukin-6 play a role in ruptured abdominal aortic aneurysm? World J. Surg. 32, 55-61 (2008).

28. Dawson, J. et al. Aortic aneurysms secrete interleukin-6 into the circulation. J. Vasc. Surg. 45, 350-356 (2007).

29. Dawson, J., Cockerill, G., Choke, E., Loftus, I. \& Thompson, M. M. Aortic aneurysms as a source of circulating interleukin-6. Ann. N. Y. Acad. Sci. 1085, 320-323 (2006).

30. Treska, V., Topolcan, O. \& Pecen, L. Cytokines as plasma markers of abdominal aortic aneurysm. Clin. Chem. Lab. Med. 38, 1161-1164 (2000).

31. Wright, H. L., Moots, R. J., Bucknall, R. C. \& Edwards, S. W. Neutrophil function in inflammation and inflammatory diseases. Rheumatology 49, 1618-1631 (2010).

32. Habashi, J. P. et al. Angiotensin II type 2 receptor signaling attenuates aortic aneurysm in mice through ERK antagonism. Science 332, 361-365 (2011).

33. Lindsay, M. E. et al. Loss-of-function mutations in TGFB2 cause a syndromic presentation of thoracic aortic aneurysm. Nat. Genet. 44, 922-927 (2012).

34. Sawaki, D. \& Suzuki, T. Targeting transforming growth factor-beta signaling in aortopathies in Marfan syndrome. Circ. J. 77, 898-899 (2013).

35. Feng, X. H. \& Derynck, R. Specificity and versatility in tgf-beta signaling through Smads. Annu. Rev. Cell Dev. Biol. 21, 659-693 (2005).

36. Shindo, J. et al. Granulocyte-macrophage colony-stimulating factor prevents the progression of atherosclerosis via changes in the cellular and extracellular composition of atherosclerotic lesions in watanabe heritable hyperlipidemic rabbits. Circulation 99, 2150-2156 (1999).

37. Zhu, S. N., Chen, M., Jongstra-Bilen, J. \& Cybulsky, M. I. GM-CSF regulates intimal cell proliferation in nascent atherosclerotic lesions. J. Exp. Med. 206, 2141-2149 (2009).

38. Haghighat, A., Weiss, D., Whalin, M. K., Cowan, D. P. \& Taylor, W. R. Granulocyte colony-stimulating factor and granulocyte macrophage colonystimulating factor exacerbate atherosclerosis in apolipoprotein E-deficient mice. Circulation 115, 2049-2054 (2007).

39. Ye, P. et al. GM-CSF contributes to aortic aneurysms resulting from SMAD3 deficiency. J. Clin. Invest. 123, 2317-2331 (2013).

40. Kimura, T. et al. Tenascin C protects aorta from acute dissection in mice. Sci. Rep. 4, 4051 (2014).

41. Weissen-Plenz, G. et al. Aortic dissection associated with Cogans's syndrome: deleterious loss of vascular structural integrity is associated with GM-CSF overstimulation in macrophages and smooth muscle cells. J. Cardiothorac. Surg. 5, 66 (2010).

42. Kessel, A., Vadasz, Z. \& Toubi, E. Cogan syndrome-Pathogenesis, clinical variants and treatment approaches. Autoimmun. Rev. 13, 351-354 (2014).

43. Babamusta, F. et al. Angiotensin II infusion induces site-specific intra-laminar hemorrhage in macrophage colony-stimulating factor-deficient mice. Atherosclerosis 186, 282-290 (2006).

44. Brocheriou, I. et al. Antagonistic regulation of macrophage phenotype by M-CSF and GM-CSF: implication in atherosclerosis. Atherosclerosis 214, 316-324 (2011).

45. Filonzi, E. L., Zoellner, H., Stanton, H. \& Hamilton, J. A. Cytokine regulation of granulocyte-macrophage colony stimulating factor and macrophage colony-stimulating factor production in human arterial smooth muscle cells. Atherosclerosis 99, 241-252 (1993).

46. Sakai, M. et al. Glucocorticoid inhibits oxidized LDL-induced macrophage growth by suppressing the expression of granulocyte/macrophage colonystimulating factor. Arterioscler. Thromb. Vasc. Biol. 19, 1726-1733 (1999).

47. Plenz, G., Koenig, C., Severs, N. J. \& Robenek, H. Smooth muscle cells express granulocyte-macrophage colony-stimulating factor in the undiseased and atherosclerotic human coronary artery. Arterioscler. Thromb. Vasc. Biol. 17, 2489-2499 (1997).

48. Saraff, K., Babamusta, F., Cassis, L. A. \& Daugherty, A. Aortic dissection precedes formation of aneurysms and atherosclerosis in angiotensin II-infused, apolipoprotein E-deficient mice. Arterioscler. Thromb. Vasc. Biol. 23, 1621-1626 (2003).

49. Cavalcante, J. L., Lima, J. A., Redheuil, A. \& Al-Mallah, M. H. Aortic stiffness: current understanding and future directions. J. Am. Coll. Cardiol. 57, 1511-1522 (2011).

50. Tarocchi, M. et al. Carcinogen-induced hepatic tumors in KLF6 + / - mice recapitulate aggressive human hepatocellular carcinoma associated with p53 pathway deregulation. Hepatology 54, 522-531 (2011). 
51. Clausen, B. E., Burkhardt, C., Reith, W., Renkawitz, R. \& Forster, I. Conditional gene targeting in macrophages and granulocytes using LysMcre mice. Transgenic Res. 8, 265-277 (1999).

\section{Acknowledgements}

Klf6 floxed mice were provided by Genentech. We thank Yasushi Imai for human samples and Naoko Sato for technical assistance. This research was funded in part by the Ministry of Health, Labour and Welfare of Japan; Grants-in Aid from the Ministry of Education, Culture, Sports, Science and Technology of Japan and the Japan Society for the Promotion of Science through its Funding Program for World-Leading Innovative R\&D on Science and Technology (FIRST Program). This study was also supported by the National Institutes of Health National Cancer Institute (DK37340).

\section{Author contributions}

B.-K.S. conducted experiments and partially wrote the manuscript. D.S. discussed on results. S.T. conducted experiments. D.F. provided human aortic samples and performed analysis. K.A., H.A., M.A., I.M., S.L.F. and I.K. consulted on the project. R.N. and T.S. planned and supervised the project. T.S. designed the study and wrote the manuscript. All authors discussed results and commented on the manuscript.

\section{Additional information}

Supplementary Information accompanies this paper at http://www.nature.com/ naturecommunications

Competing financial interests: The authors declare no competing financial interests.

Reprints and permission information is available online at http://npg.nature.com/ reprintsandpermissions/

How to cite this article: Son, B.-K. et al. Granulocyte macrophage colony-stimulating factor is required for aortic dissection/intramural haematoma. Nat. Commun. 6:6994 doi: $10.1038 /$ ncomms7994 (2015) 